\title{
Thinking and Exploration of Constructing High - level Experimental
}

\section{Technical Team}

\begin{abstract}
Zhuo Mu
The Office of Assets and Labs Management of Southwest Jiaotong University, Chengdu, Sichuan, China, 611756
\end{abstract}

Keywords: Laboratory Team, Team Building, Exploration

\begin{abstract}
The construction of first-class experimental technical team is closely related to the development of colleges and universities. Based on the requirements of the national and the Ministry of Education, this paper analyzes the structure and level of the experimental technical team in colleges and universities, and draws up the introduction, the internal cultivation, the structure construction, the evaluation standard, the incentive reward and punishment based on the experimental technical team construction program.
\end{abstract}

\section{Introduction}

The strength of the experimental team is to cultivate a comprehensive science and technology to master the comprehensive talents and enhance the vitality of the laboratory basis. To build a teaching experiment to ensure a strong, scientific research and technology development ability, in the discipline construction can play an important role in the use of well-equipped equipment, high quality, reasonable structure, personnel stability of the experimental technical team, both laboratory construction and development of the key, but also the construction of high-level universities in colleges and universities to protect the important conditions. In order to meet the new situation of experimental teaching reform and development needs, we must strengthen the construction of innovative experimental technical team.

\section{The Requirements of Ministry of Education on the Construction of Experimental Technical Team and the Urgency of the Construction of Experimental Technical Team}

"Ministry of Education on the comprehensive improvement of the quality of higher education a number of opinions" (teach high [2012] 4) that "to match the strong laboratory staff; to enhance the level of experimental teaching; strengthen the laboratory, practice training base, practice teaching Sharing platform construction, focusing on the construction of a number of national experimental teaching demonstration center, the national college students outside the practice of education base. "Therefore, colleges and universities to break through the traditional practice teaching boundaries, optimize the design of high-level experimental teaching system to promote scientific research and practice content integration, the integration of professional teachers and practical instructors, the integration of classroom and laboratory, and strengthen the cooperation between schools and enterprises to optimize the practice of teaching process.

At present, the Ministry of Education is to national goals and strategic needs-oriented, focus on national superiority, the construction of a group of larger, interdisciplinary integration, comprehensive integration of national research base. Is gradually the national laboratory to build a 
pool of domestic and international first-class talent, the formation of representatives of the national level, recognized by international counterparts in the international community has a significant impact on the scientific and technological innovation strength, become an important national strategic and innovative forces. In the Ministry of Education issued the "Ministry of Education in 2016 points" clearly stated that "the organization of colleges and universities to undertake major national scientific infrastructure and national laboratory construction tasks, organization of university participation in major national science and technology projects." Therefore, the level of laboratory technical team construction, must adapt to the national and the Ministry of Education strategic development, must be combined with the development needs of colleges and universities and school objectives.

\section{The Status Quo of Experimental Technical Team Construction}

With the increase of the number of national and provincial teaching demonstration centers, the construction of state-level laboratories and various national engineering centers has increased year by year, and the current experimental management team cannot meet the needs of the development of the cause. There is no high level of laboratory, it is impossible to build high-level research universities. To build a high level of laboratories, we must work as soon as possible to build a master of advanced experimental teaching methods, with scientific management laboratory capabilities, to meet the needs of first-class university development of high-level experimental technical team. Since the "Twelfth Five-Year Plan", the construction of faculty and personnel in colleges and universities has achieved remarkable results. However, as a part of the teaching staff, the construction of the laboratory technical team has seriously lagged behind, which has become a bottleneck restricting the comprehensive development of teaching and scientific research in colleges and universities. It is mainly in:

The experimental technical team is seriously inadequate, the lack of high level of leading talent, irrational age structure, aging serious, the team lean yellow.

Experimental technical team construction has not been given enough attention, and full-time teachers diversified "talent training program" and "talent introduction project" compared to the experimental technical team lack of strong training and introduction measures.

The uneven structure of the title structure, no promotion space, intermediate and below the proportion of staff accounted for more. No work enthusiasm. Poor pay treatment, poor promotion channel and experimental technical team is difficult to stabilize.

The experimental teaching ability and practice of technical level and experimental teaching management achievements, innovation and reform, etc., in the title assessment and other performance evaluation has not been taken seriously.

The level of laboratory management of the two units uneven, lack of communication, security problems prominent.

\section{The Program Exploration to Build Experimental Technical Team}

Construction Principles. Combined with the reform of the personnel system of the school, through the establishment of post management, the formation of conducive to the introduction of high-level experimental technical personnel, the stability of the laboratory technical backbone of the good environment; the formation of performance and capacity level-oriented evaluation mechanism; optimize the experimental technical team structure, the overall quality and level of the experimental technical team. 
Optimize the construction of basic platform, optimize the allocation of resources, improve the efficiency of laboratory and equipment use, promote the construction of experimental teaching platform and the construction of public service platform, promote the construction of laboratory equipment and related technology research and development, give full play to the laboratory and the base of experimental technical personnel improve the practical ability to improve the level of experimental teaching and public service.

Improve the quality of experimental teaching, open channels, combined with advanced experience at home and abroad to improve the overall level of the existing experimental technical team so that they can grasp and use the latest experimental technology theory and means to effectively enhance the level of experimental teaching and quality, Innovation and development.

Construction Object. Experimental technical team refers to the teaching laboratory, scientific research laboratory, public test processing service platform or discipline base and other units, engaged in experimental teaching and guidance, laboratory construction and management and laboratory safety precautions, analysis and testing, equipment and equipment operation and maintenance, technical support and other staff, mainly by the experimental teachers, experimental technicians, laboratory management and laboratory technical workers.

Experimental teacher refers to the experimental teaching as the main job responsibilities, in line with the qualifications of college teachers and the experimental teacher is an important part of the school full-time teachers. Is mainly responsible for the completion of the experimental teaching of students, and actively do a good job in laboratory construction and experimental teaching reform.

Experimental technical staff refers to the part of the experimental teaching, experimental guidance, experimental preparation, instrument operation and management as the main job responsibilities of the staff. It is mainly responsible for experimental teaching, experimental guidance work, responsible for the operation and management of large-scale equipment, functional development and utilization, the preparation of experiments and self-made experimental teaching aids.

Laboratory management staff refers to the daily management of the laboratory, coordination and other business management work as the main job responsibilities of the staff. It is mainly responsible for laboratory equipment, equipment, storage and maintenance and daily management of the laboratory and the coordination of daily affairs and so on.

Construction Initiatives. Increase the introduction of efforts to attract high-level, high-quality experimental technical personnel

The establishment of "chief experimenter" post and experimental teaching key positions, with reference to enjoy the school special job treatment. To take effective measures to rely on the existing platform construction of the school, from well-known universities and large enterprises to introduce high-level, high-quality experimental technical personnel, especially in the development and improvement of equipment and equipment to make outstanding contributions, experimental ability, experimental teaching High level of high-end talent to support the development of scientific research and discipline construction, and promote scientific research platform construction and high-level equipment development, improve the level of experimental teaching and public services. The implementation of the laboratory director responsible system, to strengthen the appointment of the laboratory director of the work, openly selected a number of business and organizational skills, work seriously responsible and dedicated disciplines and academic leaders as laboratory director, presided over and planning experimental teaching reform, scientific research, laboratory construction and management.

Newly introduced or selected experimental teachers should have a doctoral degree, the new staff 
to focus on experimental teaching ability and practical technical level. For the key equipment and management of public services key positions in the development and improvement of equipment has outstanding potential of high-level experimental technical personnel, the introduction of conditions to focus on practice teaching, teaching reform results, instrument technology management related performance and level. And gradually reduce the number of staff to take the external social employment, student assistant, labor dispatch or purchase services to carry out the relevant simple maintenance and repeat the daily management.

Increase the cultivation efforts, and effectively improve the professional level of experimental technical team

The implementation of a series of training programs, and effectively stabilize the backbone of the experimental technical team, training a number of determined in the laboratory construction and management of young and outstanding talents, the construction of a university discipline construction and development, teaching and research ability, practical experience, familiar with the experiment Technology and the courage to innovate in the laboratory of young backbone team.

(Including overseas), cross-unit (school-enterprise) to carry out exchanges and cooperation, visit the training, regular seminars, organize seminars, introduce and exchange the professional and technical activities of the team, And the development of the discipline at home and abroad and cutting forward results. To strengthen the training of experimental technical personnel, including the introduction of new experiments or the introduction of new technologies and high-end equipment, induction training, professional foreign language training, training in the form of in-service and full-time combination, long and short-term combination of the way, training content Should focus on improving the level of experimental teaching and technology to improve the maintenance of large-scale equipment testing, functional development and operation and management level. Update and expand the knowledge structure of laboratory technical staff, reinforce the theoretical basis of experimental teaching, improve the professional level and practical skills. Arrange outstanding experimental technical staff and technical backbone to go abroad well - known institutions and research institutions to study and study.

In the full-time or part-time experimental technical personnel in the selection of a high ideological and political awareness, academic level, experimental teaching experience and organizational management capacity of senior professional and technical positions as experimental teaching and research work leaders, the formation of experimental technology innovation team, Through the old and green to send help, and actively create conditions to give full play to the role of the team.

Advocate high-level talent leading laboratory construction, presided over the experimental teaching reform, leading the teaching direction, set up experimental teaching and research team, carry out project research, promote teachers and experimental technical team personnel exchanges and cooperation, promote theoretical teaching and experimental teaching organic combination and The benign interaction between the team, choose the main direction of experimental technology research, access to new experimental technology research results. Encourage instructors to undertake experimental teaching tasks according to the needs of experimental teaching, scientific research and teaching reform projects, especially to set up experimental courses with innovative content.

Clear job tasks, optimize the professional and technical evaluation criteria. Clear the experimental teaching positions, scientific research and experimental positions, precision valuable equipment management positions, equipment maintenance positions, laboratory management positions and other positions of the duties and tasks, the development of scientific and rational 
experimental technical team personnel recruitment methods. In order to improve the efficiency of employment, some experimental technical assistance, such as instrument processing, laboratory equipment maintenance work can try to purchase services.

To further optimize the experimental team of professional and technical promotion criteria, open the experimental series is a high-level assessment of the channel, according to the needs of the work, with certain conditions of the experimental technical staff can be transferred to full-time experimental teachers. The appointment of posts, promotion highlights the outstanding experimental skills and practical work performance.

Improve the evaluation mechanism, the establishment of experimental technology special incentives, stable experimental technical team. Establish and improve the assessment system. To take the experimental technical ability, performance and results of the main, and the level of theoretical research combined with the principle that the main study of experimental teaching reform, design and development of new experiments, transformation of the development of new equipment, development of new features, participate in project development, master key technologies, the ability to solve key problems and equipment management and maintenance level, the assessment results as job appointment, promotion, compensation and reward and punishment of the important basis.

Improve the status of the experimental technical staff in the school, appropriate to improve the treatment of benefits, the stability of the laboratory technical team income level, with reference to the teacher series to enjoy the job allowance, to strengthen the assessment, the implementation of incompetent personnel, poor quality, not suitable for experimental technical staff exit mechanism The introduction of incentive mechanism, the implementation of target management, and fully mobilize the experimental staff of the work of enthusiasm, initiative and creativity. Encourage and promote the experimental technical staff to actively participate in the development of experimental technology, funded experimental technicians and teachers engaged in experimental technology development, the development of large-scale equipment, experimental teaching self-control and experimental teaching reform.

The establishment of experimental technology special incentives mobilizes the experimental technical staff to carry out the enthusiasm of technological innovation. Encourage experimental technicians to publish experimental teaching and research papers to improve their academic level. Encourage experimental technicians to develop experimental technology results widely used in teaching, to encourage the Institute of experimental technology and teaching results combined with the declaration.

In summary, we can steadily create a number of high-quality teaching demonstration center, build a high level of experimental technology platform to improve the quality of experimental teaching, scientific research and experimental equipment, the use of efficiency. And through the continuous training of experimental technicians and the introduction of high-quality talent, creating an age structure, knowledge structure, academic structure, title structure more scientific and rational, combined with a relatively stable and modern teaching philosophy, master advanced experiments Teaching methods, with scientific management laboratory capacity, able to adapt to the development needs of first-class university high-level experimental technical team.

\section{References}

[1] Song Shijun. Analysis and Research on the Job Satisfaction of Experimental Teachers in Colleges and Universities[J]. Experimental Technology and Management, 2012 [9]: 200-203. 
[2] Yang Chunyong.Study on Strengthening the Construction of Experimental Technical Team in Colleges and Universities in the New Period[J]. Experimental Technology and Management, 2016 [6]: 1-3.

[3] Liu Yan, Meng Wei, Shao Yan, etc. College of experimental technology team[J]. Laboratory Research and Exploration, 2012, 31 (12): 181-183.

[4] Yun Tingting, Luo Yifan. Investigation and analysis of the status quo of experimental technicians in colleges and universities[J]. Experimental Technology and Management, 2013,30 (5): 197-199.

[5] Chen Wenqian, Song Jun, Zhaoyong Jia. Exploration and research on the construction of experimental technical team in colleges and universities[J]. Experimental Technology and Management, 2013, 30 (3): 190-192. 